\title{
TIN WHISKER FORMATION ON SMALL OUTLINE TRANSISTORS ASSEMBLED USING BISMUTH-CONTAINING LEAD-FREE SOLDER ALLOYS AFTER LONG- TERM AMBIENT TEMPERATURE, HIGH HUMIDITY STORAGE PART 3: IN-DEPTH CHARACTERIZATION AND MECHANISMS
}

\author{
André M. Delhaise ${ }^{1 *}$, Stephan Meschter², Polina Snugovsky', Jeff Kennedy ${ }^{* * *}$, \\ Zohreh Bagheri' \\ ${ }^{1}$ Celestica Inc., Toronto, ON, Canada \\ ${ }^{2} B A E$ Systems, Endicott, NY, USA
}

\begin{abstract}
With the introduction of environmental legislation such as the Restriction of Hazardous Substances (RoHS), lead (Pb)-free materials have made their way into the electronics manufacturing industry. One issue that has emerged is that $\mathrm{Pb}$-free solder alloys can initiate and grow tin whiskers under specific conditions. These whiskers are thin, highly conductive filaments which have the potential to grow and can cause field failures in many applications. Most concerning with respect to tin whiskering are high reliability applications such as aerospace, automotive, and medical.

Bismuth (Bi) is being considered for inclusion in solder alloys to replace the current industry standard (SAC 305) and provide improved thermomechanical and vibration reliability. In this paper, we discuss whisker formation of several Bi-bearing alloys after long-term (12,000 hours), ambient high humidity $\left(25^{\circ} \mathrm{C} / 85 \%\right.$ $\mathrm{RH})$ storage. Three alloys containing $\mathrm{Bi}$, in addition to SAC 305 $(\mathrm{Sn}-3.0 \mathrm{Ag}-0.5 \mathrm{Cu})$, were considered. These alloys were Violet (Sn$2.25 \mathrm{Ag}-0.5 \mathrm{Cu}-6.0 \mathrm{Bi})$, Sunflower $(\mathrm{Sn}-0.7 \mathrm{Cu}-7.0 \mathrm{Bi})$, and Senju (Sn$2.0 \mathrm{Ag}-0.7 \mathrm{Cu}-3.0 \mathrm{Bi})$. The boards were fabricated with electroless nickel immersion gold (ENIG) and immersion tin ( $\mathrm{ImmSn}$ ) finishes and populated with parts having $\mathrm{Cu}$ and $\mathrm{Fe} 42 \mathrm{Ni}$ alloy leads and chip parts, with half of assemblies cleaned and half cleaned and contaminated with low levels of $\mathrm{NaCl}$.

This paper is the third in a series of three in which we share more in-depth characterization of features of interest from the small outline transistor (SOT) inspection. Discussion regarding the role of $\mathrm{Bi}$ in the overall stress state of the joint will also be provided.
\end{abstract}

Keywords: Tin whisker, nucleation, growth, corrosion, ambient temperature, high humidity, lead-free solder, bismuth, SAC

\section{BACKGROUND}

The elimination of lead $(\mathrm{Pb})$ from consumer electronics has resulted in an increased emphasis on tin whisker risk mitigations in aerospace and defense systems using dual-use commercial/ aerospace components [1]. Environmental prohibitions of lead in commercial electronics have made these electronic parts and assemblies become more susceptible to tin whiskering. Tin whisker shorting issues were known to be an issue decades ago and at that time whisker issues were solved by the addition of lead into tin. Unlike consumer electronics, aerospace systems can have high consequences of failure and are exposed to many kinds of environmental conditions that promote whisker growth. Some conditions of concern are thermal cycling, vibration, shock, humidity, salt fog, sulfur rich environments, rework, and long term storage. Figure 1 shows several sources of compressive stress in a typical tin plated lead and solder joint.
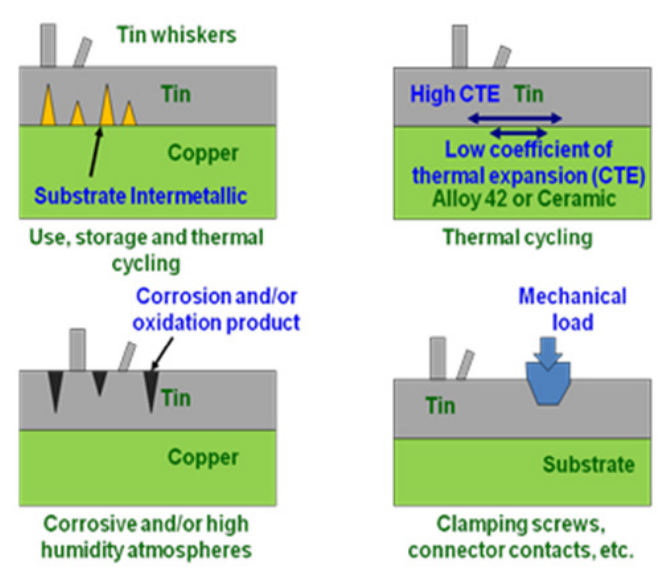

Figure 1: Sources of compressive stress contributing to whisker growth.

The dynamic recrystallization model provides a useful means to describe whisker growth [2]. An interesting aspect of the dynamic recrystallization model is that for a given temperature and grain size if the compressive stress in the tin is either too low or too high, whisker growth does not occur.

Although lead has demonstrated effectiveness at reducing whisker propensity, tin alloying elements can either increase or decrease whisker growth in Sn plating [3][4]. A short duration Sn plating study indicated that $\mathrm{Bi}$ addition tended to retard whisker growth [5]. However, prior soldered assembly tin whisker testing

\footnotetext{
* Currently employed at Envista Forensics

** Currently employed at ZESTRON Americas
} 
revealed that the entire material system of the lead-free solder joint must be considered when evaluating tin whisker growth (e.g. lead material, lead finish, solder alloy, board pad finish, board pad material, and the type/location of intermetallics within the joint) [6]. Solder can have significant whisker growth due to corrosion between different intermetallics in the alloy when contamination is present [7]. The whisker propensity of bismuth containing lead-free alloys in the present evaluation is a lower stress longer term evaluation than the previously completed high temperature high humidity testing [8][9]. Here an $25^{\circ} \mathrm{C} / 85$ percent relative humidity environment is used, similar to the soldered assembly tin whisker growth test previously performed on SAC305 (Sn3.0Ag-0.5Cu) [10]. This paper is the third of three parts detailing cross-section and Energy Dispersive X-Ray Spectroscopy (EDX) analysis of noteworthy features observed during the inspection discussed in the previous two papers. In addition, screening results from the two other test vehicles will be provided. Finally, we will comment on the role of $\mathrm{Bi}$ in whiskering as it relates to the stress state in the joint.

\section{METHODOLOGY}

Test Vehicle, Assembly, Cleaning, Contamination, and Exposure

Custom test vehicles were used for whisker growth testing. The individual printed circuit boards (soldered twelve at a time on a panel) are $6 \mathrm{~cm} \times 6 \mathrm{~cm} \times 2.36 \mathrm{~mm}$ thick double sided glass epoxy with one ounce copper external base layers and finished with either immersion tin ( $\mathrm{ImmSn}$ ) or immersion gold over electroless nickel (ENIG), both in accordance with IPC-6012.

The types of test vehicles were assembled: SOT (small outline transistor) (Figure 2), QFP (quad flat pack) (Figure 3) and BGA/ CAP (ball grid array/capacitor) (Figure 4). Details on the part types are given in the corresponding section of Part 1 of this work. The boards on the panels were soldered using solder pastes composed of the alloys and flux shown in Table 1. The SAC305 assemblies were soldered with a peak reflow temperature of $240{ }^{\circ} \mathrm{C}$, while the bismuth containing alloys had a peak reflow temperature of 226 to $228{ }^{\circ} \mathrm{C}$ (as measured at the board surface).

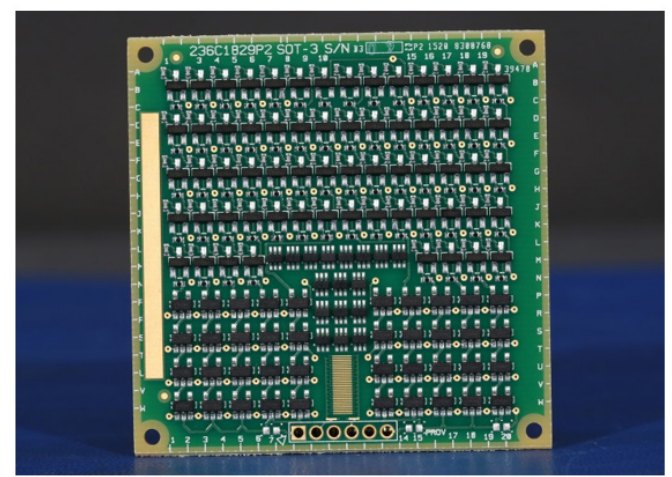

Figure 2: SOT test vehicle.

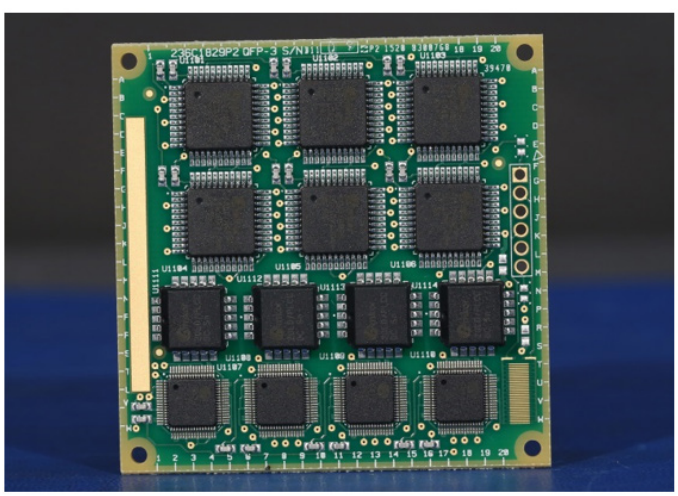

Figure 3: QFP test vehicle.

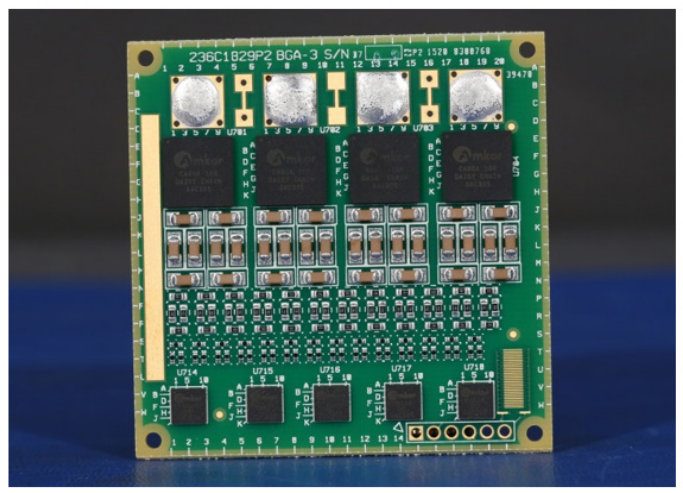

Figure 4: BGA/CAP test vehicle.

After soldering, the boards were cleaned with a conventional in-line cleaner. Next, selected boards were re-contaminated by immersion in pans with solution of $160 \mathrm{ppm} \mathrm{NaCl}$ in deionized water. Based on prior work, the resulting assembly contamination level of the purposely contaminated assemblies is expected to be near 5 ppm Cl- by ion chromatography with a total concentration of approximately $12 \mu \mathrm{g} /$ in 2 equivalent $\mathrm{Cl}$ - as measured by resistivity of solvent extraction [10]. Assemblies were exposed to low temperature high humidity $(\mathrm{ATHH}) 25^{\circ} \mathrm{C} / 85 \%$ relative humidity $(\mathrm{RH})$ simulated long term storage.

Table 1: Solder assembly alloys and fluxes.

\begin{tabular}{|c|c|c|}
\hline Solder & $\begin{array}{c}\text { Composition } \\
\text { (weight percent) }\end{array}$ & Flux \\
\hline SAC305 & 96.5-Sn, 3-Ag, 0.5-Cu & INDIUM8.9HF \\
\hline Senju M42 & $\begin{array}{c}\text { 94.25-Sn, } 2-\mathrm{Ag}, 0.75-\mathrm{Cu}, \\
3-\mathrm{Bi}\end{array}$ & INDIUM8.9HF \\
\hline Sunflower & 92.3-Sn, 0.7-Cu, 7-Bi & INDIUM8.9HF \\
\hline Violet & $\begin{array}{c}\text { 91.25-Sn, 2.25-Ag, 0.5-Cu, } \\
6-\mathrm{Bi}\end{array}$ & INDIUM8.9HF \\
\hline
\end{tabular}

For further details concerning these processes, please refer to the corresponding section(s) in Part 1 of this paper series. 


\section{Whisker Inspection}

A Hitachi S-3000 scanning electron microscope (SEM) was used for the inspection. The first inspection was performed after 1,000 hours. Following the inspection, the samples returned into the chamber and re-inspected after an additional 3,000 hours for a total of 4,000 hours $(1,000 \mathrm{~h}+3,000 \mathrm{~h})$. Then the samples were returned to the chamber again and re-inspected after an additional 8,000 hours for a total of 12,000 hours $(1,000 \mathrm{~h}+$ $3,000 \mathrm{~h},+8,000 \mathrm{~h})$.

The boards were inspected to obtain whisker nucleation and length statistics. An inspection was done for each combination of alloy (SAC, Senju, Sunflower, Violet), surface finish (ENIG, ImmSn) and level of cleanliness (clean and contaminated). All or portions of the following short hand may be used to reference the configuration: (Finish-Solder-Board-Part-Reference Designator-Lead).

Full inspections were only completed on the SOT boards; screening inspections were completed for the QFP and BGA/ CAP boards. For the latter, results from the full inspection will be provided in a future paper.

Further details on the inspection procedure are given in Parts 1 and 2 of this paper series.

\section{Cross-Sectioning and Electron Dispersive X-Ray Spec- troscopy (EDX)}

Several regions underwent cross-sectioning to examine the underlying metallurgy and better understand the causes of whisker growth. These regions were cut from the board using a diamond wire saw. Care was taken to avoid disturbing the whisker growth on adjacent parts. These were then mounted in epoxy and cross-sectioned using a series of progressively finer $\mathrm{SiC}$ paper, followed by diamond paste and colloidal silica polish to reveal the microstructural features. These were then imaged both optically as well as in SEM. Some regions (not necessarily cross-sectioned) underwent EDX to characterize the elemental composition.

\section{RESULTS}

Non-Whisker Stress Relaxation Growths

Several types of non-whisker stress relaxation growths were observed. In some cases, needle - like structures were observed without the characteristic striations or growth rings typically present on whiskers (Figure 5 to Figure 7). The longer needle-like structures were on the order of 100 microns (Figure 5 and Figure 6). Sometimes faceted growth was observed near the base of the needle growth and in one image was faceted features observed on top of the needle (Figure 7).

Faceted growth without a needle-like structure was also observed on the pad edge (Figure 8). Faceted growth was previouly observed on SAC305 solder joints after long term relatively benign simulated power cycling thermal cycling (Figure 9) [9]. Since the growth was in the small channel between the solder mask and the pad and had surrounding parts, an insitu EDX analysis could not be performed and the growth had to be removed. The growth was primarily $\mathrm{Sn}$ and $\mathrm{O}$ with a small Bi containing particle.

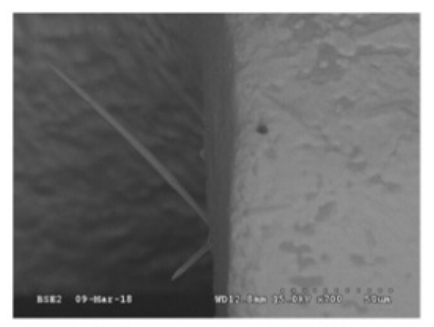

(A) $700 \mathrm{x}=50 \mu \mathrm{m}$

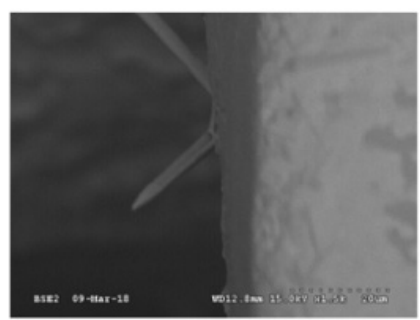

(B) $1500 x=20 \mu \mathrm{m}$
Figure 5: $12,000 \mathrm{~h}$ inspection showing needle like structures on the bottom of the lead 100.8 and 24 microns long at the board pad edge on contaminated Imm Sn board pads with Senju solder (ImSnSenju-2- SOT3-U36-Lead 3 shown).

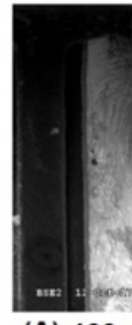

(A) $100 x$

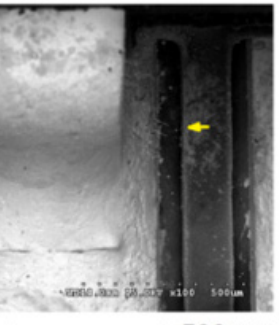

500 um

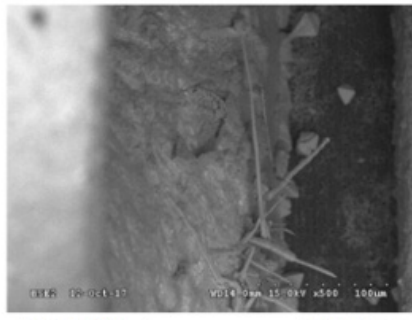

(B) $500 x$
Figure 6: 12,000h inspection showing needle like structures at the board pad edge on contaminated Imm Sn board pad with Violet solder. The needle lengths in this cluster are: 125.1, 54.6, 20.2, 20.5, 59.1, 38.3, 37.6, 58.1, 20.7, 44.9, and 16.5 microns. (ImSn-Violet-2CSOT5-U18-Lead 2 shown).

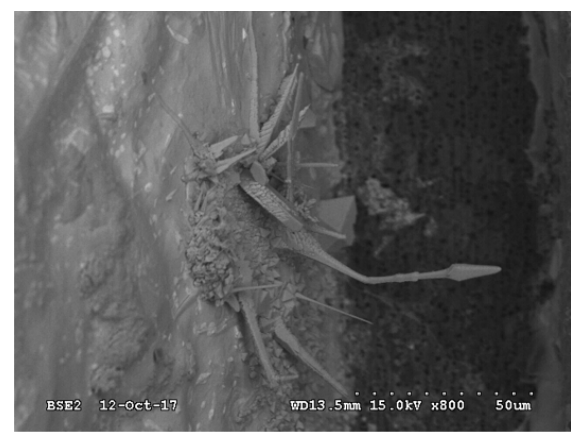

Figure 7: Needle like structures combined with faceted growth at the board pad edge observed during the $12,000 \mathrm{~h}$ inspection on contaminated Imm Sn board pad with Violet solder. The needle lengths in this cluster are: $65.3,30.7,28,14.2,24.6,23.6,12.3,13.5$, 37.3, 17.2, 20.1, and 27 microns. (ImSn-Violet-2C-SOT5-U11-Lead 5). 

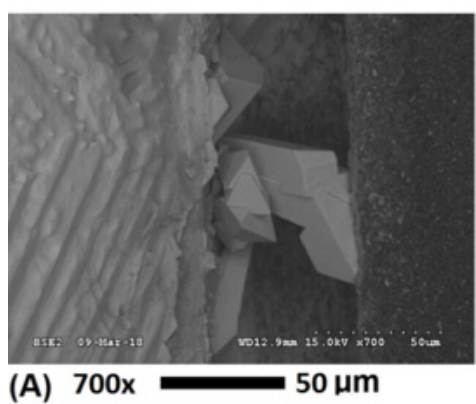

8000 hrs, Senju, ImSn, U22, lead 3(2) 44737

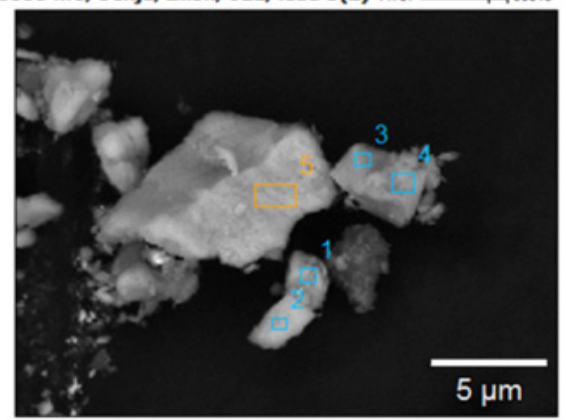

8000 hrs, Senju, ImSn, U22, lead 3(3) 44737 다

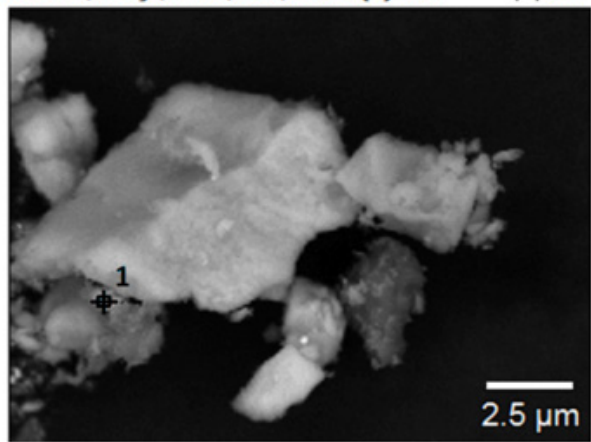

(B) After removal from board for EDX

\begin{tabular}{|c|c|c|c|}
\hline Weight\% & O-K & S-K & Sn-L \\
\hline lead 3(2)_pt1 & 29.94 & 0.19 & 58.86 \\
\hline lead 3(2)_pt2 & 33.32 & & 54.91 \\
\hline lead 3(2)_pt3 & 32.05 & & 45.18 \\
\hline lead 3(2)_pt4 & 26.96 & & 50.85 \\
\hline lead 3(2)_pt5 & 13.71 & 0.27 & 82.03 \\
\hline
\end{tabular}

\begin{tabular}{|c|r|c|c|c|}
\hline Weight\% & O-K & Cu-K & Sn-L & Bi-M \\
\hline Lead 3(3)Pt1 & 20.25 & 1.92 & 69.45 & 1.66 \\
\hline
\end{tabular}

Figure 8: Faceted block like growth observed during the $12,000 \mathrm{~h}$ inspection on the Imm Sn pad on a cleaned Senju soldered SOT3; (A) close-up of faceted growth and (B) EDX examination of the growth after removal from the board. (ImSn-Senju-2- SOT3, U22, lead 3 shown).
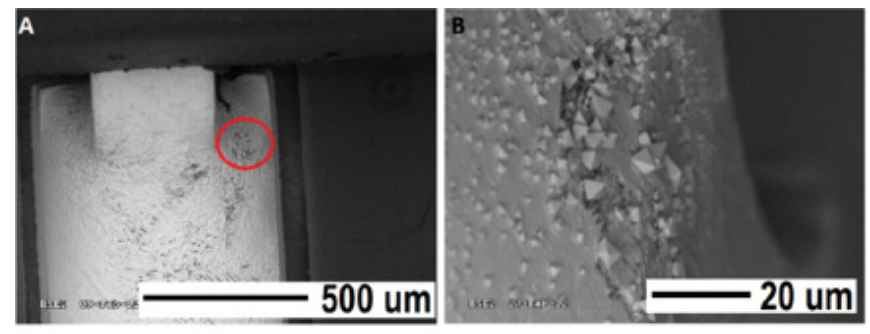

Figure 9: Faceted growth observed during +50 to $+85 \mathrm{C}$ simulated power cycling thermal cycling during the SERDP WP1753 test [9].

A unique tin growth developed on the side of of an Imm Sn pad with a relatively large diameter comprised of multiple columns somewhat resembling petrified wood (Figure 10).

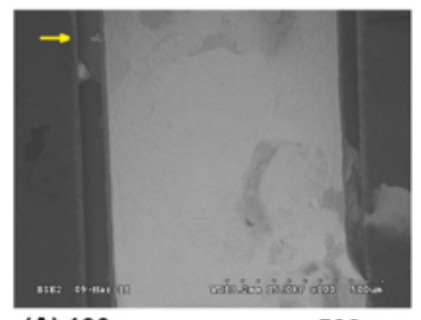

(A) $100 \mathrm{x}$

500 um

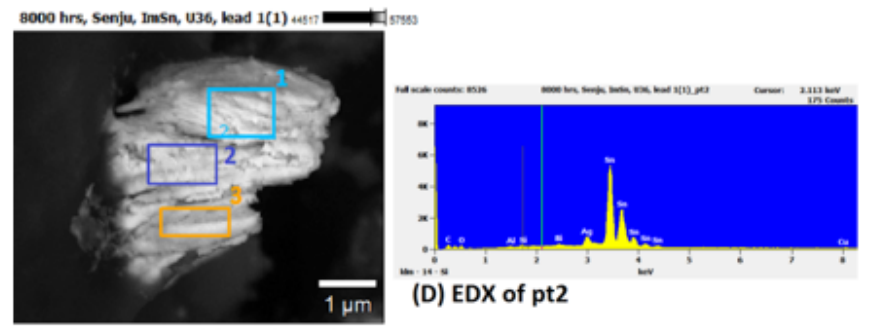

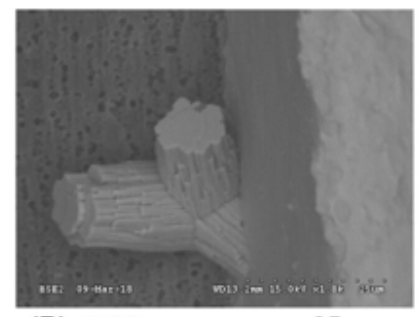

(B) $1800 x$

$25 \mu \mathrm{m}$
(C) After removal from board for EDX

\begin{tabular}{|l|c|r|r|r|r|}
\hline Weight \% & O-K & Cu-K & Ag-L & \multicolumn{1}{|c|}{ Sn-L } & Bi-M \\
\hline pt1 & 5.42 & & 2.00 & 87.89 & 2.04 \\
\hline pt2 & 5.00 & 0.74 & 6.48 & 84.08 & 1.82 \\
\hline pt3 & 11.05 & & & 83.26 & 2.20 \\
\hline
\end{tabular}

Figure 10: Tin growth with an appearance like petrified wood on the pad edge of a cleaned Senju assembly observed during the $12,000 \mathrm{~h}$ inspection; (A) overall image of pad, (B) close-up of growth (arrow in A), (C) growth after removal for EDX analysis, and (D) EDX spectra from pt2. (ImSn-Senju-2-SOT3- U36-Lead 1 shown).

\section{Cross-Section and EDX Results} 4000h Contaminated ImmSn-SAC305-SOT5 corrosion

The corrosion on the SAC305 solder follows the Sn between the higher silver regions (Figure 11). 


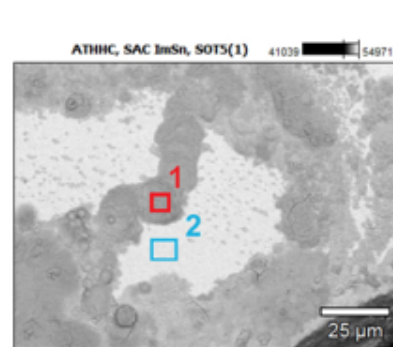

(A) EDX Locations

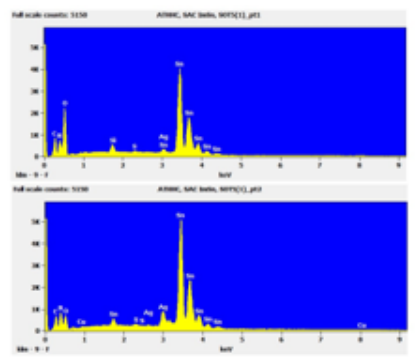

(B) EDX Spectra

\begin{tabular}{|l|l|l|l|l|l|l|l|l|}
\hline $\begin{array}{l}\text { Weight } \\
\%\end{array}$ & $\mathrm{C}$ & $\mathrm{N}$ & $\mathrm{O}$ & $\mathrm{Si}$ & $\mathrm{S}$ & $\mathrm{Cu}$ & $\mathrm{Ag}$ & $\mathrm{Sn}$ \\
\hline pt1 & 6.71 & 4.61 & 23.12 & 1.18 & 0.34 & & 0.94 & 63.11 \\
\hline pt2 & 4.49 & 5.50 & 7.40 & & 0.35 & 1.48 & 6.41 & 74.36 \\
\hline
\end{tabular}

Figure 11: 4000h inspection showing EDX of corrosion on a contaminated SOT5 with SAC305 solder on an Imm Sn board finish; (A) EDX locations and (B) EDX spectra.

4000h Clean Imm Sn-Sunflower-SOT6 Surface phases

The higher Bi-content Sunflower has Bi and $\mathrm{SnCu}$ phases in the larger SnBi regions (Figure 12).

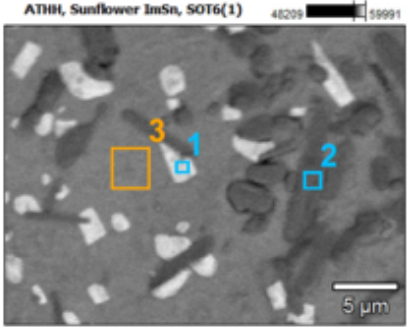

(A) EDX Locations

(B) EDX Spectra

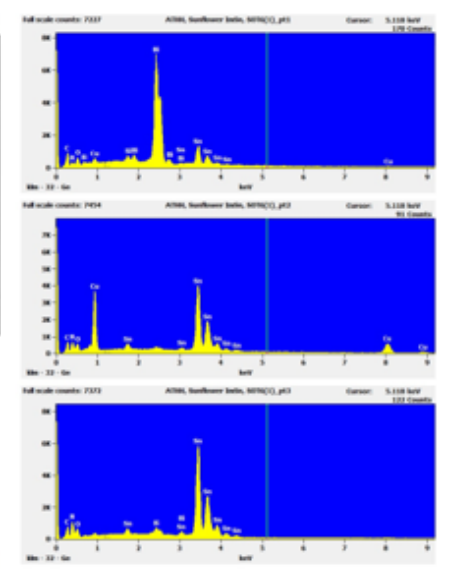

\begin{tabular}{|l|l|l|l|l|l|l|l|}
\hline Weight $\%$ & $\mathrm{C}$ & $\mathrm{N}$ & $\mathrm{O}$ & $\mathrm{Si}$ & $\mathrm{Cu}$ & $\mathrm{Sn}$ & $\mathrm{Bi}$ \\
\hline pt1 & 7.47 & 3.06 & 2.52 & 0.78 & 1.94 & 20.42 & 63.82 \\
\hline pt2 & 7.56 & 4.76 & 4.71 & & 24.43 & 58.54 & \\
\hline pt3 & 5.61 & 6.13 & 6.93 & & & 77.77 & 3.56 \\
\hline
\end{tabular}

Figure 12: 4000h inspection showing Bi particles on the surface of a SOT6 Sunflower soldered Imm Sn finished board; (A) EDX locations and (B) EDX spectra.

12,000h clean Imm Sn-Sunflower-SOT5-U28 Whisker and Plate structure cross-sections

The whisker and plate structures shown in Figure 35 in Part 1 were evaluated by EDX and cross-sectioning. The EDX results of the whisker (Figure 13A\&B) show that the top is $\mathrm{Bi}$ and the base is $\mathrm{Sn}$ with 2.1Bi. The EDX results of the plate (Figure $13 \mathrm{C} \& \mathrm{D})$ indicate that the plate is oxidized $\mathrm{Sn}$ with $\mathrm{Cu}$ and $\mathrm{Bi}$. The cross-section of lead 3 was obtained while grinding to lead

4 (Figure 14) and showed very little solder on the lead knee. XC1 on lead 4 shows that the whisker was above a Cu6Sn5 layer and that the whisker contained $\mathrm{Sn}, \mathrm{Cu}$ and $\mathrm{Bi}$ (Figure 15). The intermetallic is less than one micron thick and suggests that the whisker growth may have stopped due to the elimination of tin in that area. Grinding further, XC2 shows a crack between the thin plate and the lead (Figure 16). XC3 shows a section into a larger plate structure (Figure 17) where the plate can be seen on top of a solder layer and the plate has cracks within it. The corroded surface has no dissolved $\mathrm{Bi}$ in the $\mathrm{Sn}$. The plate is oxidized $\mathrm{Sn} 2.1 \mathrm{Cu}$ with some $\mathrm{Sn} 1.6 \mathrm{Bi} 2.7 \mathrm{Cu}$ particles on top of a solder layer $\mathrm{Sn} 2.1 \mathrm{Bi} 2.9 \mathrm{Cu}$ solder.
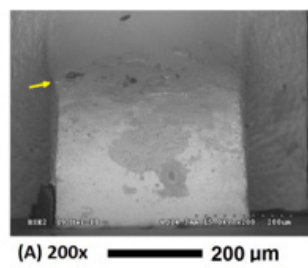

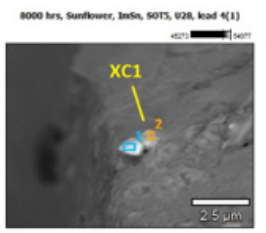

(B) EDX Lead 4(1) and section XC1

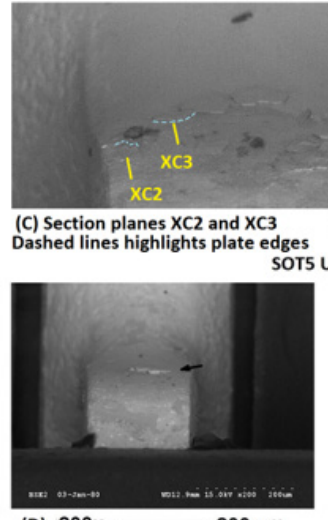

(D) $200 \mathrm{x}=200 \mu \mathrm{m}$
SOT6 473 Lead 6

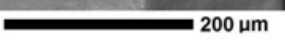
T5 U28 Lead 4

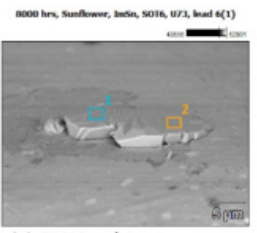

(E) EDX Lead 6

\begin{tabular}{|c|c|c|c|c|c|}
\hline $\begin{array}{c}\text { Weight \% } \\
\text { (C omitted) }\end{array}$ & O-K & Si-K & Cu-K & Sn-L & Bi-M \\
\hline U28, lead 4(1)_pt1 & 12.82 & 0.64 & 3.68 & 10.72 & 69.05 \\
\hline U28, lead 4(1)_pt2 & 14.03 & & 3.30 & 78.89 & 2.10 \\
\hline & & & & & \\
\hline Weight \% & O-K & Si-K & Cu-K & Sn-L & Bi-M \\
\hline U73, lead 6(1)_pt1 & 26.26 & 2.88 & 0.68 & 65.62 & \\
\hline U73, lead 6(1)_pt2 & 24.64 & 4.77 & 1.71 & 57.80 & 3.56 \\
\hline
\end{tabular}

Figure 13: Images and EDX analysis on SOT5 and SOT6 parts on a clean Imm Sn board with Sunflower solder after 12,000h; (A) overall SOT5 Cu lead showing whisker (black arrow), (B) EDX locations on whisker with Bi cap (see black arrow in A) and section plane XC1 location, (C) electronic image zoom of (A) showing several plate structures and section planes XC2 and XC3, (D) overall of SOT6 Ni42Fe lead with a similar plate structure, and (E) EDX of plate structure (see arrow in C). (images from ImSn-Sunflower-2) 


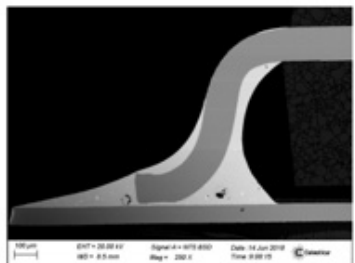

(A) $250 \mathrm{x}-100 \mu \mathrm{m}$

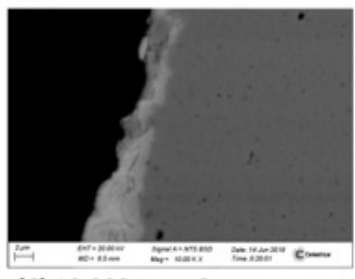

(C) $10,000 x-2 \mu \mathrm{m}$
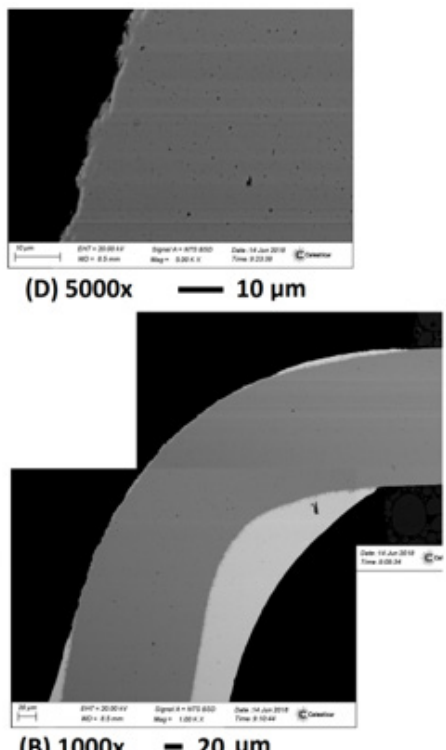

(B) $1000 \mathrm{x} \quad-20 \mu \mathrm{m}$

Figure 14: Cross-section of clean SOT5 U28 Lead 3 (polished before grinding to lead 4) after 12,000h; (A) overall, (B) composite close-up lead knee and top, (C) close-up of the solder transition from the bulk to the lead, and (D) close-up of the knee.
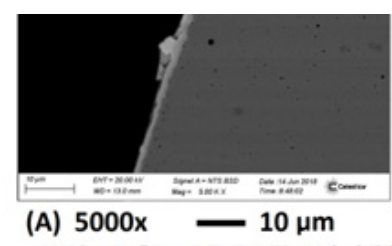

8000 hrs,

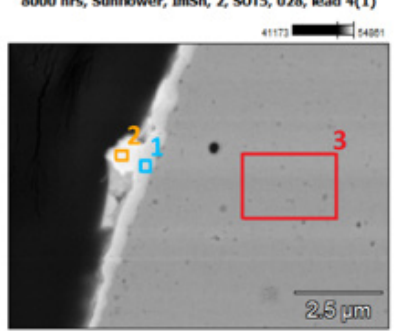

(C) EDX locations

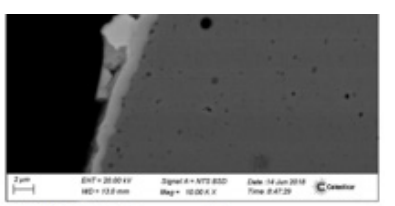

(B) $10,000 \mathrm{x}-2 \mu \mathrm{m}$

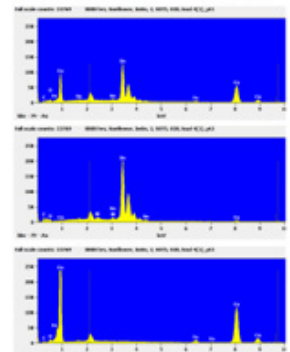

(D) EDX Spectra

\begin{tabular}{|c|c|c|c|c|c|}
\hline $\begin{array}{c}\text { Weight\% } \\
\text { (C and Si } \\
\text { omitted) }\end{array}$ & O-K & Fe-K & Cu-K & Sn-L & Bi-M \\
\hline lead4(1)_pt1 & 5.44 & 0.90 & 42.95 & 48.60 & \\
\hline lead4(1)_pt2 & 6.01 & & 2.84 & 86.19 & 2.90 \\
\hline lead4(1)_pt3 & 1.89 & 2.37 & 93.32 & & \\
\hline
\end{tabular}

Figure 15: Cross-section of plane XC1 in Figure 13 and EDX of whisker on clean SOT5 U28 Lead 4 after 12,000h; (A) whisker overall, (B) close-up, (C) EDX locations, and (D) EDX spectra.
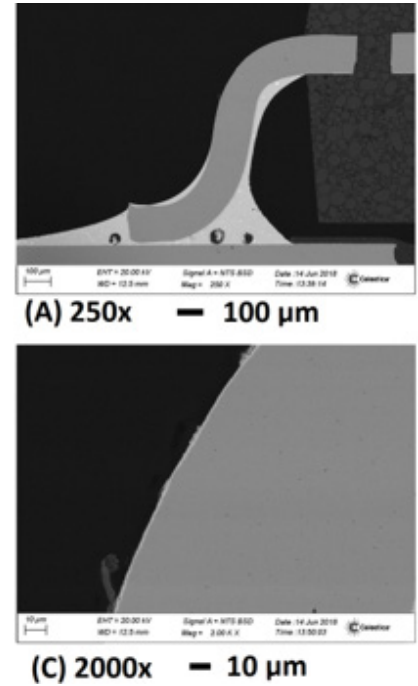

(C) $2000 \mathrm{x}-10 \mu \mathrm{m}$

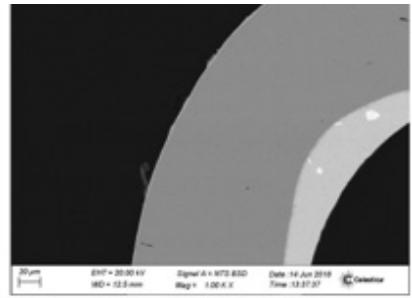

(B) $1000 \mathrm{x}-20 \mu \mathrm{m}$

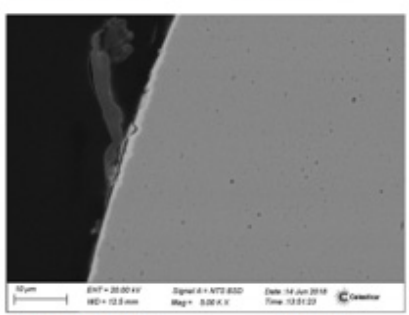

(D) $5000 \mathrm{x}-10 \mu \mathrm{m}$

Figure 16: Cross-section of plane XC2 in Figure 13 on clean SOT5 U28 Lead 4 after 12,000h; (A) overall, (B), (C) and (D) increasing magnification images of knee.
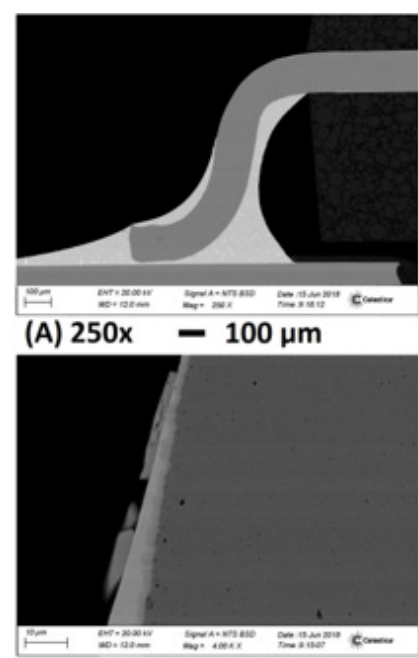

(C) $4000 \mathrm{x} \quad-10 \mu \mathrm{m}$
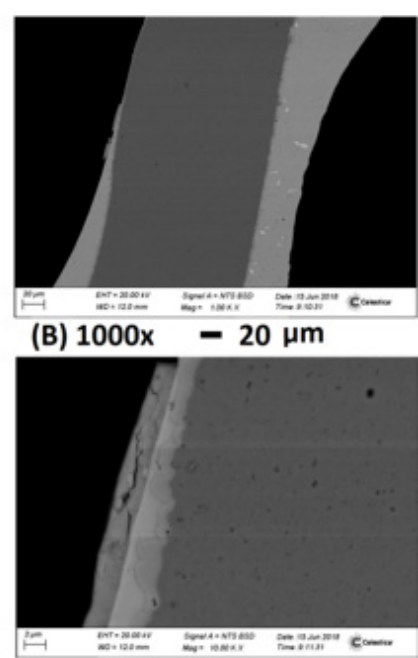

(D) $10,000 x-2 \mu \mathrm{m}$

Figure 17: Cross-section of plane XC3 in Figure 13on clean SOT5 U28 Lead 4 after 12,000h; (A) overall, (B), (C) and (D) increasing magnification images of knee. 
8000 hrs, Sunflower, ImSn, SOTS, U28, Lead, slice 3(1)

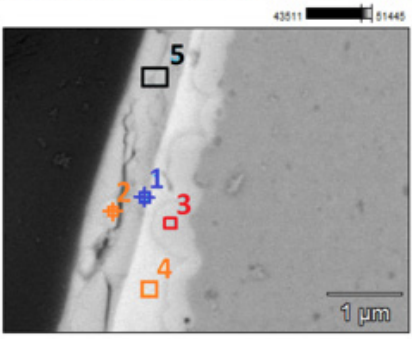

(A) EDX Locations

(B) EDX

Spectra

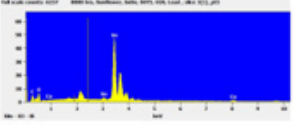

Weight\%

\begin{tabular}{|c|c|c|c|c|}
\hline $\begin{array}{c}\text { Weight } \% \\
\text { (C and Si omitted) }\end{array}$ & O-K & Cu-K & Sn-L & Bi-M \\
\hline slice3(1)_pt1 & 12.20 & 3.19 & 81.53 & 1.63 \\
\hline slice3(1)_pt2 & 12.26 & 2.69 & 81.10 & 1.59 \\
\hline slice3(1)_pt3 & 4.60 & 35.31 & 56.80 & 1.35 \\
\hline slice3(1)_pt4 & 6.29 & 2.86 & 87.54 & 2.08 \\
\hline slice3(1)_pt5 & 16.85 & 2.13 & 78.15 & \\
\hline
\end{tabular}

Figure 18: EDX of cross-section plane XC3 of Figure 13 on clean SOT5 U28 Lead 4 after 12,000h; (A) Locations and (B) spectra (images from ImSn-Sunflower-2).

\section{2,000h contaminated Imm Sn-Senju-SOT3-U36}

Examination of a partially corroded whisker at the top of a SOT3 lead on a contaminated Senju soldered assembly is shown in Figure 19. The cross-section through the whisker and the adjacent area where the corrosion/non-corroded lead surface demarcation occurs is shown in Figure 20. The solder thickness in this region along the knee is on the order of one micron. The EDX of the corrosion demarcation regions is provided in Figure 21. As was previously observed in the plate section, the corroded area does not contain $\mathrm{Bi}$; while the non-corroded surface contains 1.9 weight percent $\mathrm{Bi}$.

The EDX of the whisker region (Figure 22) is more complex. The corrosion consists of $\mathrm{Sn}$ with $\mathrm{O}, \mathrm{Fe}, \mathrm{Ni}, \mathrm{Cu}$ and $\mathrm{Bi}$. The light particle (point 1) has a larger Ni concentration. The corrosion near the whisker has a porous structure and the corrosion around the whisker diameter contains radial cracks (point 5).

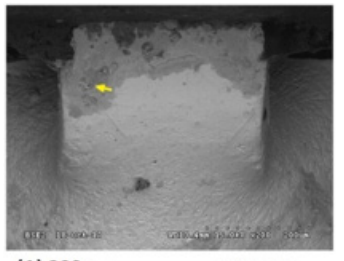

(A) 200x

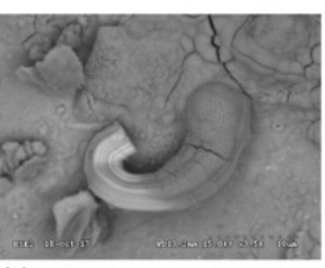

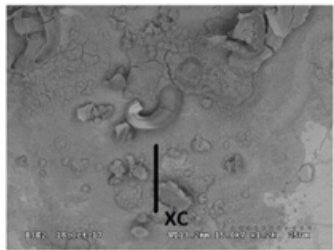

(B) 1200x $25 \mu \mathrm{m}$
(C) $3500 \mathrm{x}$

Figure 19: Images of a partially corroded whisker on a contaminated SOT3 on an Imm Sn board soldered with Senju solder after 12,000h; (A) overall, (B) close-up of whisker (see arrow in A) and location of cross-section plane, and $(C)$ higher magnification image of whisker. The left side has not corroded. (ImSn-Senju-2C-SOT3-U36-lead 1 shown).
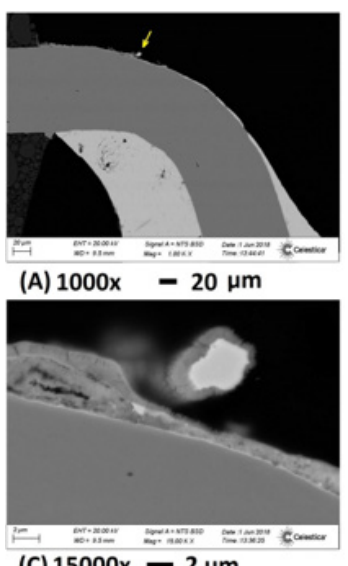

(C) $15000 \mathrm{x}-2 \mu \mathrm{m}$

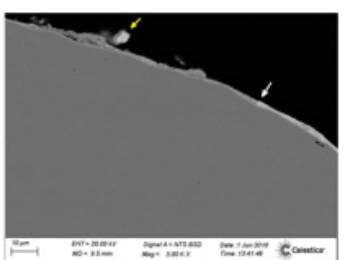

(B) $3000 \mathrm{x} \quad-10 \mu \mathrm{m}$
Figure 20: Cross-section of plane XC in Figure 19 of whisker and corrosion line of a contaminated SOT3 assembled with Senju solder after 12,000h; (A) overall with whisker shown by yellow arrow, (B) close-up near whisker (yellow arrow) with corrosion demarcation along plating (white arrow), and (C) higher magnification image of the whisker. (ImSn-Senju-2C-SOT3-U36-lead 1 shown). 

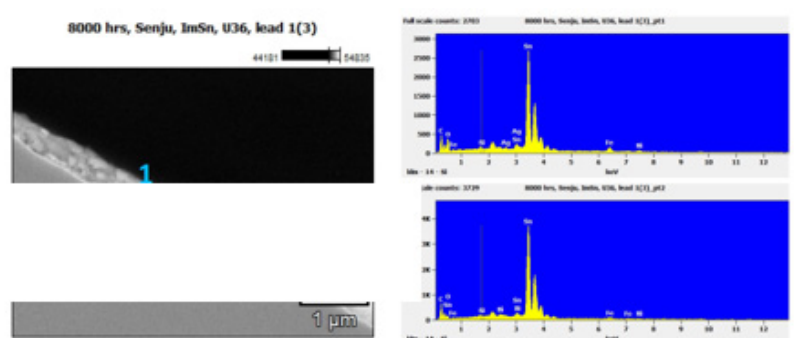

(A) EDX locations

(B) EDX spectra

\begin{tabular}{|c|c|c|c|c|c|c|}
\hline $\begin{array}{c}\text { Weight\% } \\
\text { (C and Si } \\
\text { omitted) }\end{array}$ & O-K & Fe-K & Ni-K & Ag-L & Sn-L & Bi-M \\
\hline Lead1(3)pt1 & 17.98 & 2.86 & 1.44 & 1.56 & 70.95 & \\
\hline Lead1(3)pt2 & 4.36 & 1.45 & 1.19 & & 86.19 & 1.93 \\
\hline
\end{tabular}

Figure 21: EDX from the surface corrosion demarcation area in cross-section plane XC in Figure 19 (white arrow) of a contaminated SOT3 assembled with Senju solder after 12,000h; (A) EDX locations and (B) EDX spectra (ImSn-Senju-2C-SOT3-U36-lead 1 shown).

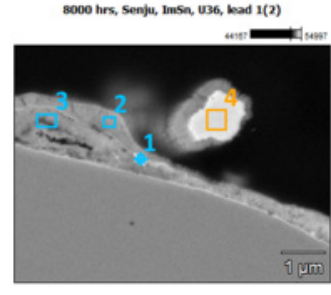

8000 hrs, Senju, Imsa, u36, lead 1(4)

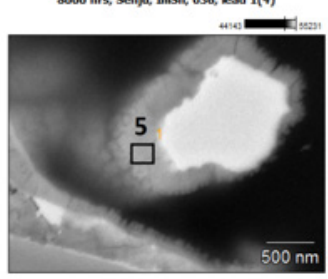

(A) EDX locations
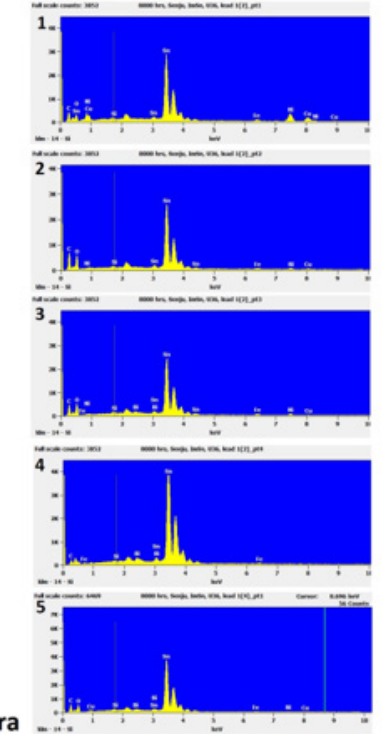

(B) EDX spectra

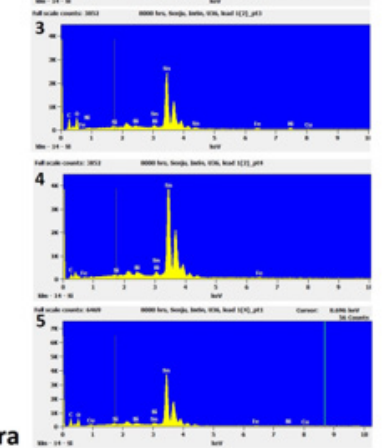

\begin{tabular}{|c|c|c|c|c|c|c|}
\hline $\begin{array}{c}\text { Weight\% } \\
\text { (C and Si } \\
\text { omitted) }\end{array}$ & O-K & Fe-K & Ni-K & Cu-K & Sn-L & Bi-M \\
\hline Lead1(2)pt1 & 10.72 & 1.52 & 12.09 & 6.75 & 63.45 & \\
\hline Lead1(2)pt2 & 21.63 & 1.18 & 2.21 & 1.70 & 66.03 & \\
\hline Lead1(2)pt3 & 21.06 & 1.64 & 2.03 & 1.44 & 66.17 & 2.10 \\
\hline Lead1(2)pt4 & & 0.75 & & & 94.93 & 3.05 \\
\hline Lead1(4)pt5 & 17.68 & 0.93 & 1.36 & 1.18 & 72.26 & 1.79 \\
\hline
\end{tabular}

Figure 22: EDX from the whisker area in cross-section plane XC in Figure 19 (yellow arrow) of a contaminated SOT3 assembled with Senju solder after 12,000h; (A) EDX locations and (B) EDX spectra (ImSn-Senju-2C-SOT3-U36-lead 1 shown).

\section{Clean ImSn Senju SOT5 Pad oxidation}

During the $4000 \mathrm{~h}$ inspection, surface oxidation was also observed where the solder was thin on the pad edge where there was no Bi (Figure 23). This suggests that formation of corrosion products that displace the Bi can also occur early in life.
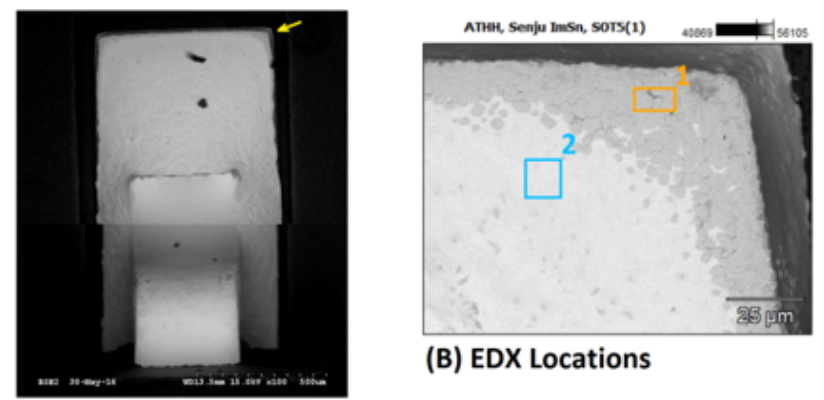

(B) EDX Locations
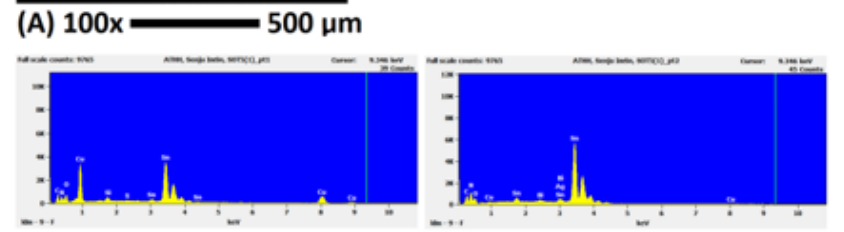

(C) EDX Spectra

\begin{tabular}{|l|l|l|l|l|l|}
\hline Weight \% & $\mathbf{C}$ & $\mathbf{N}$ & $\mathrm{O}$ & $\mathrm{Si}$ & $\mathrm{S}$ \\
\hline pt1 & 9.20 & 3.89 & 5.99 & 1.12 & 0.24 \\
\hline pt2 & 4.42 & 9.38 & 4.90 & & \\
\hline
\end{tabular}

\begin{tabular}{|l|l|l|l|l|}
\hline Weight $\%$ & $\mathrm{Cu}$ & $\mathrm{Ag}$ & $\mathrm{Sn}$ & $\mathrm{Bi}$ \\
\hline pt1 & 28.24 & & 51.31 & \\
\hline pt2 & 2.31 & 1.73 & 76.12 & 1.14 \\
\hline
\end{tabular}

Figure 23: 4000h inspection EDX of a clean Imm Sn pad corner soldered with Senju; (A) overall composite, (B) close-up of pad corner with EDX locations and (C) EDX Spectra. (ImSn-Senju-SOT5U15-lead 4 shown).

\section{QFP Screening Inspection}

The full results from this inspection (data and images) are given in Appendix $\mathrm{H}$ from the original conference publication of this work; there was a wide range in whisker count across the set of leads that were inspected. Future inspections will be more comprehensive and examine a larger set from each population. Observations from the inspection are as follows:

- The longest whisker was on ENIG, Senju, PLCC and was $29.5 \mu \mathrm{m}$ in length.

- Most of the measured whiskers were found on Imm Sn assemblies.

- The Imm Sn, Sunflower PLCC samples produced the most (total and measured) whiskers.

- Only one long whisker was found on QFP64.

- Many hollow whiskers were observed, but they are not included in the total whisker count.

Some representative images (both ImmSn PLCC parts) from Senju and Sunflower are shown in Figure 24 and Figure 25. The Sunflower lead in particular had a large number of whiskers on the lead shin (L4) which warranted further investigation. 


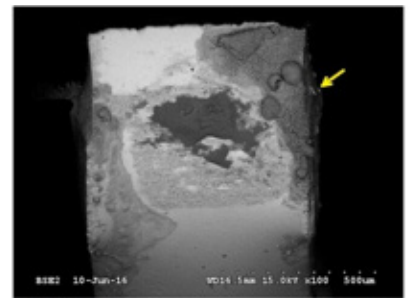

(A) 100x

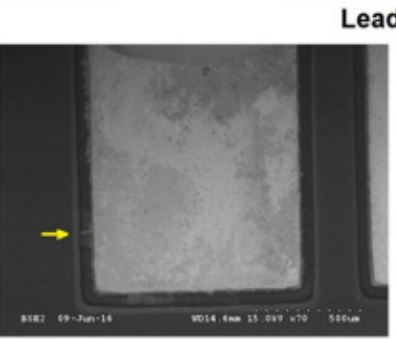

(C) $70 x$

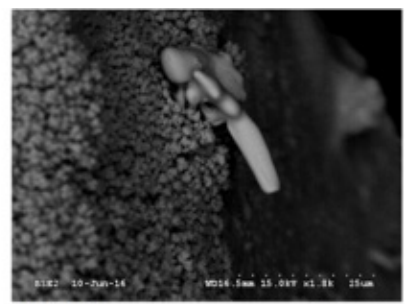

(B) $1800 x$

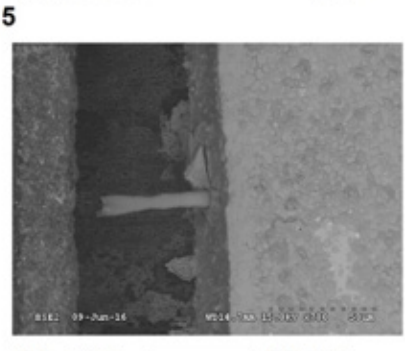

(D) $700 x$
$50 \mu \mathrm{m}$

\section{Lead 20}

Figure 24: 4000h corrosion and whisker growth on Senju PLCC part on ImmSn board; (A) Lead with substantial corrosion, (B) Hollow whisker indicated by arrow in (A), (C) Pad with moderate corrosion and (D) Hollow whisker indicated by arrow in (C).

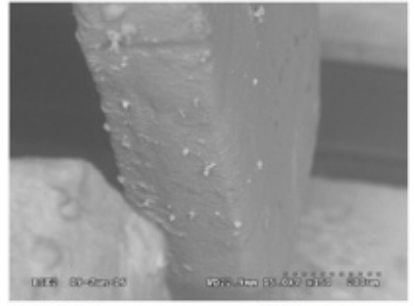

(A) $150 x$

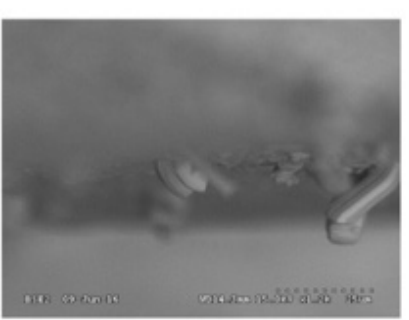

(C) $1200 \mathrm{x}=150 \mu \mathrm{m}$

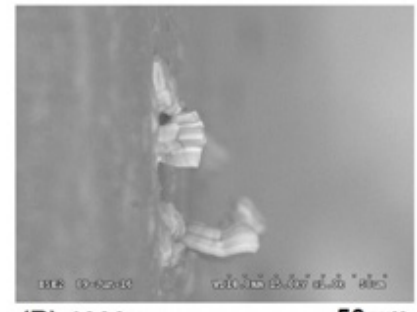

(B) $1000 x$

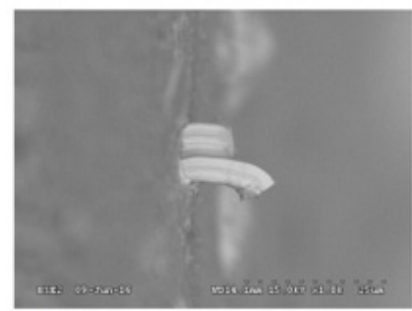

(D) 1800x 25 um
Figure 25: 4000h whisker growth on Sunflower PLCC part on ImmSn board; (A) Lead with many whiskers on L4 and (B-D) Higher magnification images of some of the whiskers on the lead in (A).

It is known that reflowing Sn plating will remove features such as residual plating stress and trapped organic contaminants from the plating process. As indicated earlier in this paper, SAC 305 assemblies were reflowed at a peak temperature of $240^{\circ} \mathrm{C}$, while the assemblies with Bi-bearing alloys were reflowed at a peak temperature between $226^{\circ} \mathrm{C}$ and $228^{\circ} \mathrm{C}$. The peak temperature of the latter is below the melting point of $\mathrm{Sn}$, and thus plating artifacts are more likely to remain after reflow on parts on these assemblies, particularly if the solder cannot wick up the entire lead (Figure 26). A quick inspection of PLCC parts (at location
L3) in the SEM indicated that this was indeed the case - the part assembled with Sunflower paste retained most of its original plating structure, while the SAC 305 sample appeared to reflow (Figure 27). This was further supported by EDX; parts reflowed with $\mathrm{SAC}$ showed regions richer in $\mathrm{Cu}$, indicating a reaction occurred between the Sn plating and $\mathrm{Cu}$ lead base metal (which would only occur if the Sn were to melt), while the Sunflower sample did not show any regions with $\mathrm{Cu}$.

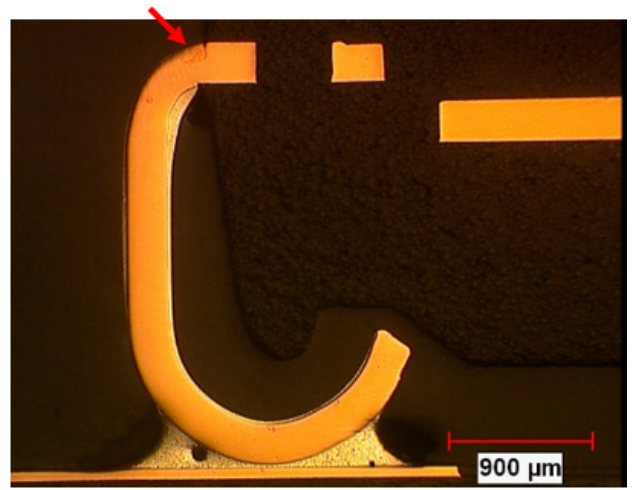

Figure 26: Cross-section of as-assembled PLCC part. Arrow indicates approximate location of SEM/EDX analysis.

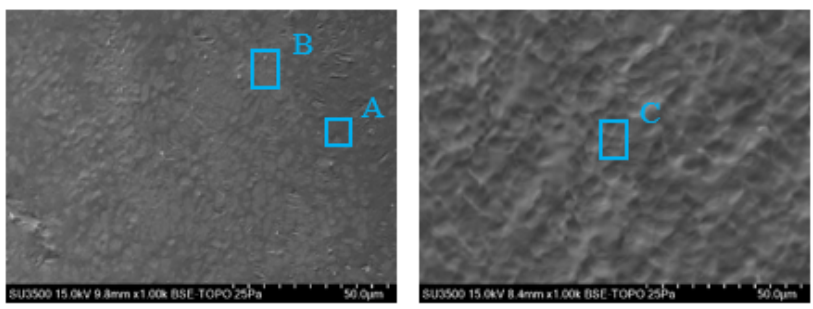

\begin{tabular}{|c|c|c|c|}
\hline Site & Sn (wt\%) & Cu (wt\%) & Si (wt \%) \\
\hline A & 96.4 & 2.0 & 1.6 \\
\hline B & 71.3 & 27.3 & 1.4 \\
\hline C & 99.0 & 0.0 & 1.0 \\
\hline
\end{tabular}

Figure 27: SEM images of plating morphology and EDX results on asassembled PLCC joints at L3; (left) SAC 305 and (right) Sunflower

These results indicate that while residual plating artifacts may contribute to whisker formation, the reaction of the Sn with the $\mathrm{Cu}$ base metal in SAC 305 to form IMCs may also contribute to whisker growth via the coarsening of these particles over time.

\section{BGA/CAP Screening Inspection}

Whiskers were found on the capacitors and resistors during a screening inspection of contaminated assembles at 12,000h. No whiskers were found on the corresponding cleaned assemblies. Some of the whiskers on the order of 50 microns were observed (Figure 28) and were often above the main solder fillet (Figure 29). In some cases, however, whisker growth and faceted growth was observed from the solder near the ceramic (Figure 30). Additional images are provided in Appendix I from the original conference publication of this work. 


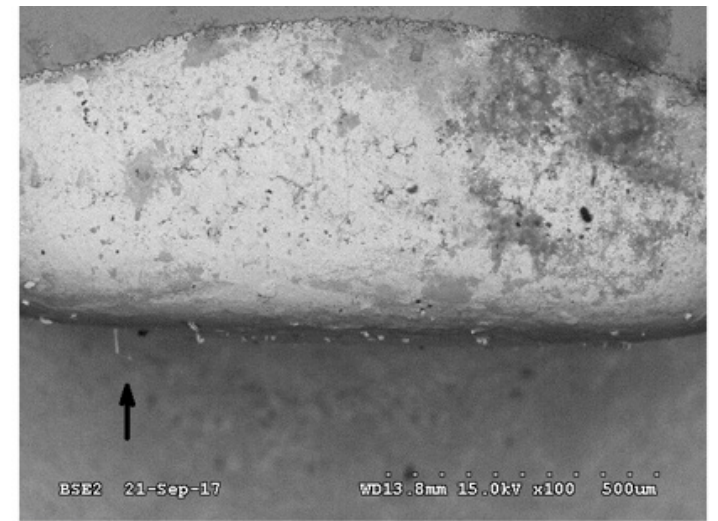

(A) $100 x$

$500 \mu \mathrm{m}$

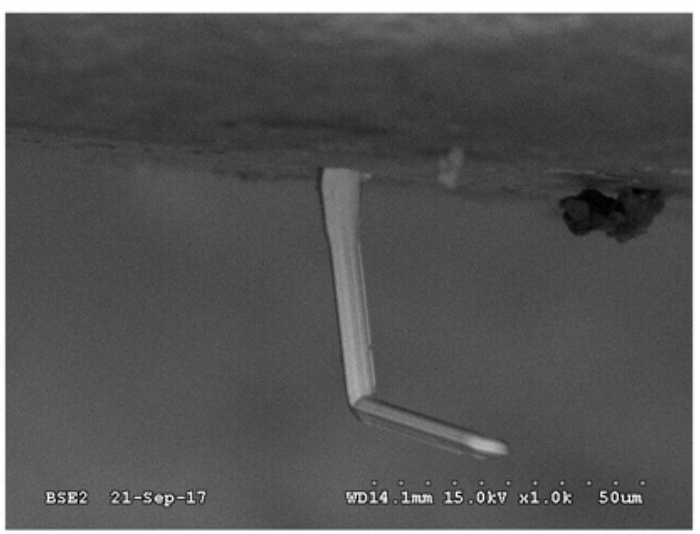

(B) $1000 x$

$50 \mu \mathrm{m}$

Figure 28: 12,000h inspection showing whisker growth from a larger capacitor on a contaminated BGA/CAP board; (A) overall image and (B) close-up of whisker (arrow in A). (ImSn-Violet-Cap-3C shown).

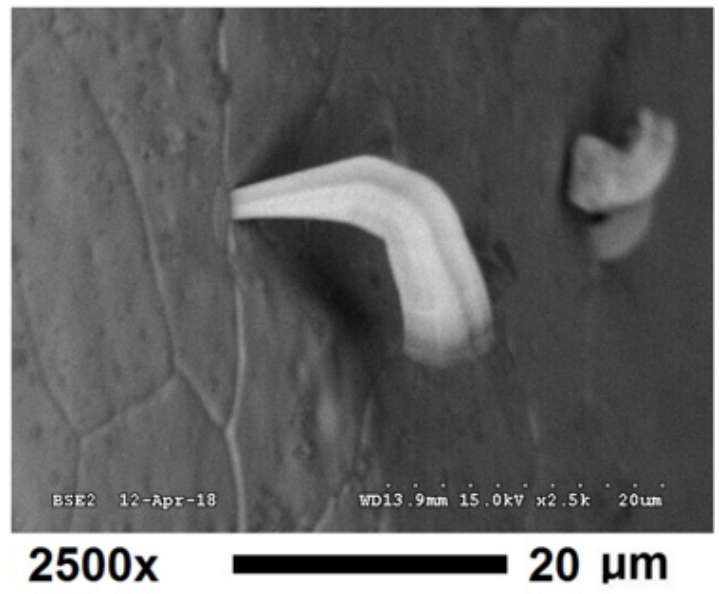

Figure 29: 12,000h inspection showing whisker growth from 1206 capacitor on a contaminated BGA/CAP board; (A) overall image and (B) close-up of whisker. (ImSn-Violet-2C-big cap 1 shown).
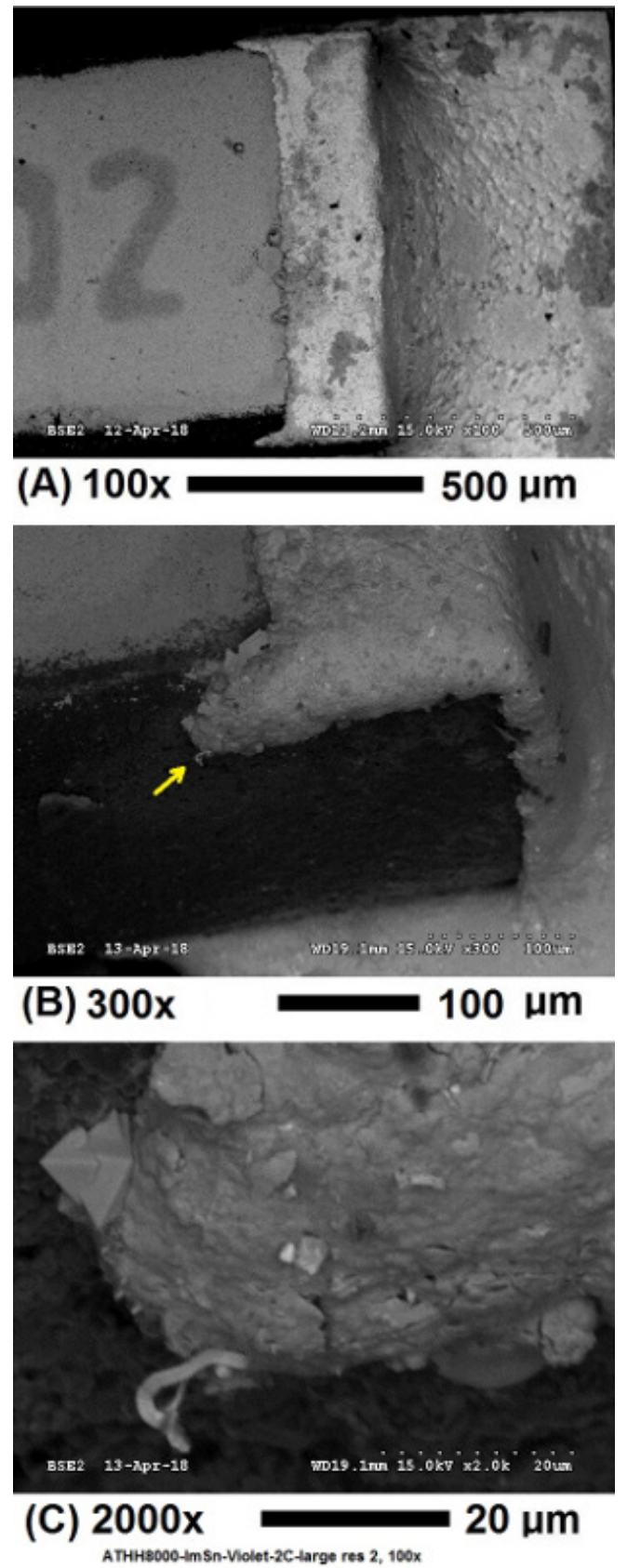

Figure 30: 12,000h inspection showing whisker growth from a resistor on a contaminated board (ImSn-Violet-2C-large res 2 shown).

\section{DISCUSSION}

Whisker Stress 'Sweet Spot'

The concept of a 'sweet spot' for stress required for whisker growth was initially proposed by Vianco [2]. The model suggests that there is some intermediate stress level in a solder joint that will produce whiskers; sufficiently high stresses will fail to produce whiskers (likely due to Sn undergoing plastic deformation). In this study, there are many factors - contamination, surface finish, lead frame material, and Bi content - which affect the total stress in the joint. It is likely that the changing trends in whisker growth with $\mathrm{Bi}$ content are due to the stress state in the joint being adjusted relative to the sweet spot. 
To summarize:

- Contamination increases stress from corrosion substantially

- Precipitation of Bi causes Sn to recrystallize (Figure 31a). This both increases stress as grain boundaries are susceptible to corrosion (Figure 31b), but also dissipates stress evenly throughout the joint and the likelihood of long whiskers (higher, more localized stress) can be reduced.

- Bi may form a galvanic couple and phase boundaries with Sn which increases stress from corrosion (Figure 31c)

- $\mathrm{Ni}$ in Alloy 42 lead and ENIG surface finish may mitigate corrosion and refine IMCs compared with Cu194 lead and ImmSn finish respectively, decreasing stress.

- Au in ENIG finish may exacerbate corrosion (galvanic) near the pad, increasing stress

- Differences in minor elements in the alloy composition such as $\mathrm{Ag}$ and $\mathrm{Cu}$ affect the volume fraction of corresponding IMCs (Ag3Sn and Cu6Sn5) in the joint and may affect stress due to corrosion and IMC coarsening.

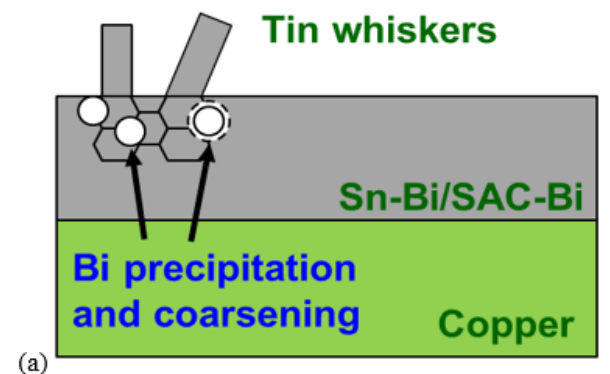

(a)

Tin whiskers

(b)
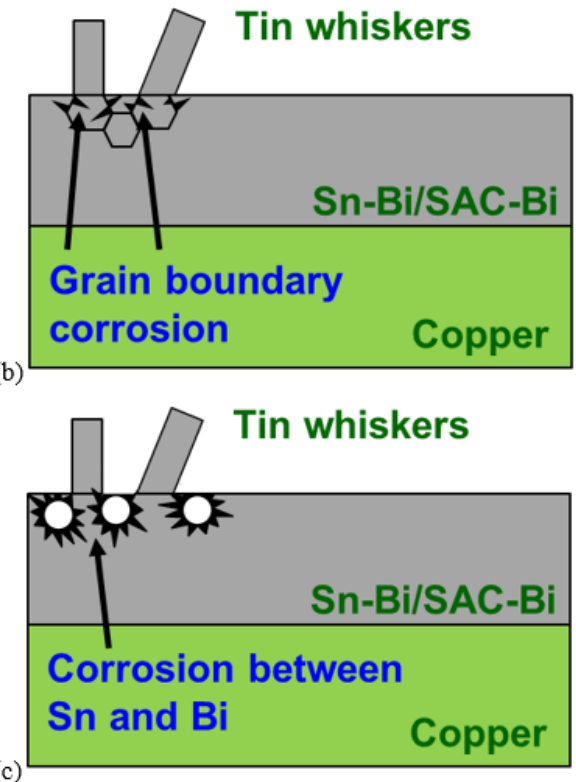

Figure 31: Schematics illustrating the effects of $\mathrm{Bi}$ on tin whisker growth; (a) Precipitation and coarsening of $\mathrm{Bi}$ over time induces Sn to recrystallize into small, uniform grain structure, (b) Increased grain boundary content in the alloy results in increased grain boundary corrosion, and (c) Corrosion (galvanic or phase boundary) of $\mathrm{Sn}$ in proximity to $\mathrm{Bi}$.
As observed in Figure 32 (also shown in Figure 13 from Part 2 of this work)Figure 32, as the Bi content in the alloy is increased, whisker density increases on Alloy 42 and decreases on Cu194. Alloy 42 contains $\mathrm{Ni}$, which may mitigate corrosion and IMC coarsening, and the stress induced is initially low. Additions of $\mathrm{Bi}$ increase the stress state (via precipitation and corrosion), but not sufficiently high enough to be 'outside' the sweet spot, resulting in increased whisker density. For Cu194, the stress state is likely initially higher than Alloy 42 as there is no $\mathrm{Ni}$ in the lead frame. Bi additions increase the stress - for Senju on ImmSn, the whisker density was observed to be very high, possibly because the total stress remained within the sweet spot. Further additions of $\mathrm{Bi}$ (for Violet and Sunflower) may raise the stress state to be higher than the sweet spot, resulting in lower density. This is a possible reason why the whisker density is higher on Alloy 42 than Cu194 for alloys with high Bi content, which is opposite to what is seen on SAC 305 joints.

This high density on the ImmSn-Senju-Cu194 combination may also be related to the interaction of corrosion product with whiskers. This combination may represent some 'optimal' corrosion conditions in which fewer numbers of whiskers are consumed or broken by corrosion. Other combinations, such as with Violet or Sunflower, may produce more whiskers than were actually observed, but corrosion of whiskers was sufficient to reduce whisker density during inspection. More frequent VPSEM inspections would likely ascertain whether this is indeed the case.

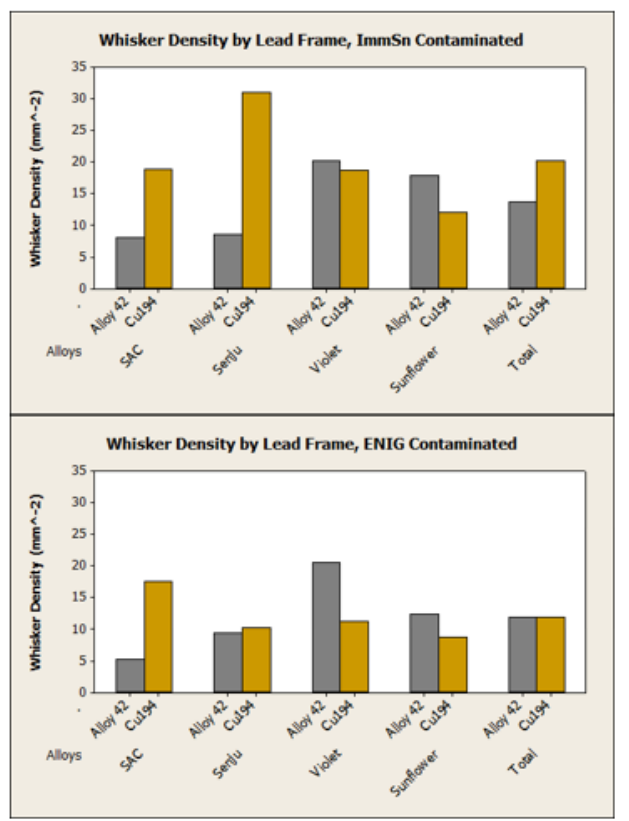

Figure 32: Whisker density on contaminated ImmSn (top) and ENIG (bottom) assemblies, organized by lead frame material for each alloy. 


\section{SUMMARY AND CONCLUSIONS}

Several key takeaways from the third paper of this study are as follows:

- Several non-whisker stress relaxation growths were observed. Further analysis to differentiate these growths from traditional whiskers is necessary and recommended.

- Cross-section and EDX results confirmed the hypothesis that in a region composed of $\mathrm{Sn}$ and $\mathrm{Bi}$, the $\mathrm{Sn}$ will preferentially corrode, displacing $\mathrm{Bi}$ out of the $\mathrm{Sn}$ oxide region.

- It is possible, though not necessarily the case, that the variations of stress caused by corrosion and IMCs (as a result of varying alloy composition) may have resulted in 'unintuitive' whisker growth statistics (such as with ENIG finishes, where the high Bi-bearing alloys produced more and longer whiskers than low or no Bi-bearing alloys).

The inclusion of Bi likely increases the stress state in the joint, due to $\beta$-Sn recrystallization as a result of $\mathrm{Bi}$ precipitation (and possible intergranular corrosion), as well as galvanic corrosion between $\mathrm{Sn}$ and Bi. These factors, along with additional sources of stress such as variations in surface finish, may shift the stress state to produce more favorable conditions for whisker growth.

Overall, the results from this study do not indicate that Bi alone may be used to mitigate against whisker growth. Careful consideration of factors such as leadframe material and surface finish, in addition to alloy composition are necessary to produce more desirable whiskering conditions. In general, reducing assembly contamination and / or the use of a conformal coating are more effective methods for mitigating tin whisker growth.

\section{FUTURE WORK}

Several ongoing and possible future work to supplement this study are as follows:

- The full inspection and analysis of the corresponding BGA/ CAP assemblies (subjected to ATHH storage) is complete and will be published in a future paper.

- In addition, high temperature, high humidity $\left(85^{\circ} \mathrm{C}, 85 \%\right.$ $\mathrm{RH})$ exposure, up to 4000 hours has been conducted on SOT and BGA/CAP assemblies. The inspections of both sets of assemblies are complete and analysis is ongoing. These results will be published in an additional future paper.

- In this study, it was difficult to quantify the contribution of $\mathrm{Bi}$ to corrosion and whisker growth, due to the effects of contamination, varying $\mathrm{Ag}$ and $\mathrm{Cu}$ content, as well as the complexity of the solder joint geometry. It may be possible to examine this more conclusively using an experiment in which no contamination is used (with more regular inspection intervals), only Bi content is varied, and using a simpler coupon geometry.

\section{ACKNOWLEDGEMENTS}

The authors would like to thank the Canadian ReMAP program, Mikaella Brillantes, University of Toronto, for assistance with PLCC inspections, Russell Brush, Celestica, for the environmental testing, Ivan Tan, Celestica, for the assembly.

\section{REFERENCES}

[1] GEIA-STD-0005-2, Standard for Mitigating the Effects of Tin Whiskers in Aerospace and High Performance Electronic Systems, SAE International, Warrendale, PA.

[2] P.T. Vianco, M.K. Neilsen, J.A. Rejent, and R.P. Grant, Validation of the Dynamic Recrystallization (DRX) Mechanism for Whisker and Hillock Growth on Sn Thin Films, Journal of Electronic Materials, Vol. 44, No. 10, 2015, pp. 4012 - 4034.

[3] G.T. Galyon, Annotated Tin Whisker Bibliography and Anthology, IEEE Trans. Packag. Manuf. Vol. 28, No. 1, January 2005, pp. 94-122.

[4] J. Nielsen and T. Woodrow, The Role of Trace Elements in Tin Whisker Growth, Project WP1751 Final Report for the Strategic Environmental Research and Development Projects (SERDP), September 22, 2013.

[5] I. Yanada, "Electroplating of Lead-Free Solder Alloys Composed of $\mathrm{Sn}-\mathrm{Bi}$ and $\mathrm{Sn}-\mathrm{Ag}$, Proc. Of the IPC Printed Circuits Expo, Long Beach USA: pp. S11-2 to S11-2-7, April 1998.

[6] S. Meschter, P. Snugovsky, Z. Bagheri, E. Kosiba, M. Romansky, J. Kennedy, L. Snugovsky, and D. Perovic, Whisker Formation on SAC305 Soldered Assemblies, JOM, vol. 66 no. 11, pp. 2320-2333, Nov. 2014 (DOI) 10.1007/s11837-014-1183-9, available on line at

http:/ /www.springer.com/home?SGWID=0-0-1003-0-0\&aqI $\mathrm{d}=2737780 \&$ download $=1 \&$ checkval $=\mathrm{c} 6 \mathrm{~d} 6 \mathrm{cb} 73 \mathrm{aec} 6 \mathrm{cca} 572 \mathrm{a} 5 \mathrm{~b} 0$ 64f23677b9

[7] P. Snugovsky, S. Meschter, Z. Bagheri, E. Kosiba, M. Romansky, and J. Kennedy, Whisker Formation Induced by Component and Assembly Ionic Contamination, Journal of Electronic Materials, February 2012, Volume 41, Issue 2, pp 204223, available for download at http:/ / link.springer.com/content/ pdf/10.1007\%2Fs11664-011-1808-5.pdf

[8] S. Meschter, P. Snugovsky, J. Kennedy, and Z. Bagheri , ReMAP Materials Project M2: High Temperature High Humidity Corrosion and Tin Whisker Evaluation of Bi containing Leadfree Alloys, International Conference on Soldering and Reliability, (ICSR) Toronto, Canada, May 10-11, 2016

[9] S. Meschter, Tin Whisker Testing and Modeling, Project WP1753 Final Report, U.S. DoD, EPA, DOE Strategic Environmental Research Programs (SERDP), November 2015, available for download at: https://www.serdp-estcp.org/ Program-Areas/Weapons-Systems-and-Platforms/Lead-FreeElectronics/WP-1753

[10] S. Meschter, E. Ekstrom, P. Snugovsky, J. Kennedy, Z. Bagheri, and E. Kosiba, Strategic Environmental Research and Development Program (SERDP) Tin Whisker Testing and Modeling: Long Term Low Temperature High Humidity Testing, International Conference on Soldering and Reliability (ICSR), Toronto, Ontario, Canada; May 19-21, 2015. 


\section{BIOGRAPHIES}

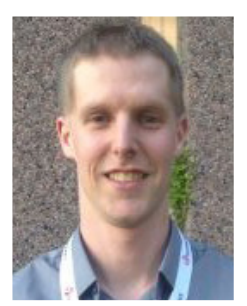

Dr. André Delhaise is currently a consultant at Envista Forensics in Toronto, Canada, where he is responsible for solving issues related to materials science in insurance losses. Previously, Dr. Delhaise was a metallurgist at Celestica, Inc., and was involved in several projects in association with the Refined Manufacturing Acceleration Process (ReMAP), which is a Canadian-led consortium of academic and industry partners focused on the commercialization of novel manufacturing technologies and processes. He completed his Ph.D. in Materials Science \& Engineering at the University of Toronto in 2018 under the supervision of Dr. Doug D. Perovic, which focused on the metallurgy of bismuth-containing lead-free solders. Dr. Delhaise also holds a Bachelor of Applied Science (BASc.) degree from the same department, obtained in 2013. He was awarded the 'Best of Proceedings' award at the SMTA International Conference in 2017 and has published several papers in refereed journals such as the Journal of Electronic Materials (JEM).

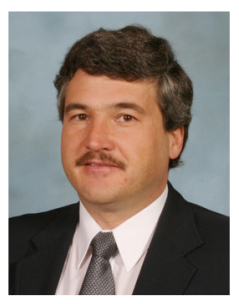

Dr. Stephan Meschter has over 30 years of experience in advanced packaging, failure analysis, and reliability testing of electronic assemblies at BAE Systems Electronic Systems in Endicott, NY. He has designed and evaluated electronic assemblies for power, flight and jet engine control systems used in spacecraft, aircraft and ground vehicles. Starting in 2004, Stephan began evaluating the commercial lead-free materials transition impact to high-reliability, high-performance aerospace and defense electronic systems. He was a member of the 2009 U.S. DoD Lead-free Electronics Manhattan Project team that published a set of best practices to mitigate the risks associated with Lead $(\mathrm{Pb})$-free electronics usage in high performance DoD systems. Since 2010, Stephan has worked with SERDP on lead-free tin whisker formation research and short circuit risk mitigation using enhanced polymer conformal coatings. He earned a bachelor's in mechanical engineering from the University of Hartford in Hartford CT in 1984, and he holds both a master's degree (1987) and a doctoral degree (2001) in Mechanical Engineering from the State University of New York in Binghamton, NY. Stephan currently participates in the IPC Lead(Pb)-free Electronics Risk Management (IPC-PERM) Council and is currently supporting revision of several SAE GEIA Lead-free Aerospace and Defense risk management standards.

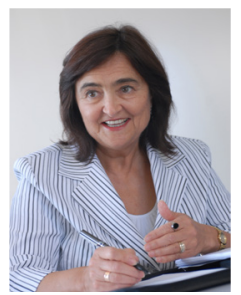

Polina Snugovsky recently served as Principal Engineer - Chief Metallurgist at Celestica. Polina was an invited subject matter expert participant in the $2009 \mathrm{~Pb}$-free Manhattan Project tasked with the risk assessment of $\mathrm{Pb}$-free electronics in Aerospace and DoD applications. Polina was an active participant in the Pbfree electronics in aerospace project group (AIA PERM) - American Institute of Aeronautics.
She was the principal investigator of two U.S. DoD Strategic Environmental Research and Development Projects (SERDP) that are examining corrosion induced whisker growth and manufacturing mitigation. She has also actively participated in NASA DoD projects. Dr. Snugovsky graduated from the State Metallurgical Academy of Ukraine and received her Ph.D. in Metallurgy, and subsequently in 1985 she earned the higher level Doctoral degree in Metallurgy and Material Science. Before she joined Celestica in 1996, she was a full professor in the department of physical metallurgy of the State Metallurgical Academy of Ukraine. She has published over 160 papers and patented new materials and processes. Polina holds several Outstanding Technical Achievement Awards, including two from Celestica and received Best International Conference Papers awards at SMTA2006, APEX2007, APEX2009, APEX2010, APEX2013 and APEX2014. In 2012 she received SMTA Member of Technical Distinction Award.

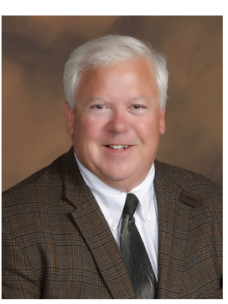

Jeff Kennedy is currently the Strategy and Business Development Manager at ZESTRON Americas. Prior to that he directed Celestica's advanced technology strategy and development initiatives, including the design and implementation of technology roadmaps for the Industrial and $A \& D$ sectors. Jeff has more than 30 years of experience in system integration, process development, PWB fabrication, and packaging in the microelectronics industry. He has engineering and management experience working within mainframe computer industry, microcircuit wire bonding and flip chip, PWB fabrication and laminate packaging substrates, and the last 16 years in contract electronics assembly. Jeff is a past President of SMTA and is an active member of both IPC \& IMAPS. 